\title{
The Big Test
}

\author{
J. Max Findlay
}

Can. J. Neurol. Sci. 2010; 37: 541-542

Bill Horsey, Toronto's St. Michael's Hospital's first neurosurgeon once told me a story about his Royal College fellowship exams. Bill had nearly completed his general surgical training under Dr. Keith Welch at St. Mike's when he was sent across the city to become Harry Botterell's first resident in neurosurgery after Harry succeeded Dr. K. G. McKenzie as head of neurosurgery at the Toronto General Hospital. The plan was for Bill to return to St. Mike's and start up a neurosurgical service. When he appeared for his fellowship examinations in 1954 the two examiners representing the two training programs in the country at that time were his very own boss Harry Botterell and Arthur Elvidge from the Montreal Neurological Institute. The oral exam quickly degenerated into jocular bantering when the candidate was able to identify not only the diagnoses of the patients whose x-rays Botterell had brought, but their names, treatments and outcomes as well.

Things had changed, but perhaps not as much as hoped for, when I took my exams in 1989. I had four examiners in total (two sets of two) instead of two, but x-rays were still randomly fished out of bags or brief cases, never before seen by the co-examiner (resulting, therefore, in two of the three persons in the room frowning at films, usually baffled) and often different cases for each candidate to keep things interesting for the examiner. I even had one examiner hand me a "Selverstone" clamp in pieces near the end of my exam, asking me to assemble it.

"Sir," I said, "I think I know what this is and what it used to be used for..." (Which was the gradual, day-by-day, "tolerancetesting" and reversible closure of the cervical internal carotid artery for the treatment of intracranial aneurysms), "And I could give it a try, but I have actually never seen one before."

"Really?" the surprised examiner said.

"Yes sir, where I trained we clipped aneurysms!" I responded, after which my co-examiner (bless his soul) interjected, "Now, let's see, we haven't used one of these things in London in at least ten years, I would guess." Whereupon my questioner declared, "But I put one in a patient last week!" I passed the exam, thank God, but spent a few sleepless nights worrying about that clamp question (results came by post-remember that?).

The examination process is enormously stressful, we all will agree. When I completed mine I swore I would never, ever, become an examiner, clearly an inhumane and cruel job. I recall fellow residents arguing that after the residency we endured that there should be no exams, simply a diploma of completion, or of survival, along with a richly deserved license to practice. Made sense to me. Most neurosurgeons until fairly recently can remember every single exam question they were asked, mainly because the written exams, which were three hours each over two days (and they still are), consisted only of maybe six questions. "Discuss the cerebellum" for about one thousand marks, along with "Discuss syringomyelia" and "Discuss, with the aid of diagrams, the middle cranial fossa" were three questions that made up one of my exams.

The "discuss" word, asking for an essay-type answer, is now forbidden in our Royal College Exams. We ask "short answer" questions, asking for a sentence or two, or maybe a short list of single word answers, probing as many points of information as possible. Each question usually contains five or six separate questions on the same topic. Many questions are now richly illustrated with diagnostic imaging, specimens and photomicrographs. And we have an exam "blueprint" to follow, making sure we cover all the topics on which neurosurgeons need to be knowledgeable, in the right proportion. AND, we have to divide up each question into the different CanMEDS competencies being tested! It is a lot of work. The hardest part is making sure you have complete and accurate answers-good questions are easy, but good answer keys and guidelines are tough!

And it is fairly thankless work. No one is going to tell you "That was a great exam!" The candidates get an opportunity (which they take great advantage of) to provide "feedback" on all aspects of their exams, and invariably report that it contained too much anatomy, too much physiology and too much pathology, none of which are considered required knowledge for competent neurosurgeons. Or at least that is what a considerable number of candidates think when surveyed, and this information is faithfully conveyed by the Royal College to the examination Chair. On top of that, the Educational Research and Development Unit (ERDU) of the Royal College scrutinizes the exams and how the candidates did with each question, providing a fairly complicated and statistical "Psychometric Report", a sort of report card on how well the examinations "performed". There is always something to improve upon.

Examiners are now required to take a course on examining provided by ERDU, the examinations have to be prepared months in advance, screened and edited by a group of examiners who have to take time off from their busy clinical practices and travel to Ottawa for that purpose (without pay), and the huge oral examination is now prepared entirely on PowerPoint. It is

\footnotetext{
From the University of Alberta Hospital, Edmonton, Alberta, Canada.

Received January 11, 2010. Final Revisions Submitted February 12, 2010. Correspondence to: J. Max Findlay, University of Alberta Hospital, Edmonton, Alberta, T6G 2B7, Canada.
} 
standardized, blueprinted, CanMEDed, translated into our other official language, and most importantly, agreed upon by the committee as being accurate, fair but challenging, and a good test of general neurosurgical competence. It never ceases to amaze me how many different yet perfectly acceptable approaches we can take to common clinical scenarios that we test on.

Despite our concerns about the humanity of the examination process, our misgivings about participating in this form of torture we ourselves had to endure, and finally the work and time involved, examiners participate eagerly, like the job, and are very good at it. They are on the candidate's side, never misleading or tricky, asking reasonable and clear questions. If nothing else, examining for the Royal College is a terrific refresher and exercise in continuing education.
I have been in the examination business a long time and think the modern process is a huge improvement from the past, and will be no less memorable to the candidates than the exams we took. I asked one of my own (successful) candidates how he found the exam last year, and he said, "Well, at least the imaging was great, and I even recognized a few of your patients in the questions!" As my mother used to say, the more things change, the more things remain the same.

J. Max Findlay is the immediate past Chair of the Royal College Examination Committee for Neurosurgery. 